\title{
Persistance and Compliance with 0steroporosis Therapies Among Women in a Commercially Insured Population in the United States
}

\author{
Lung-I Cheng, PhD; Emily Durden, PhD; Brendan Limone, PharmD; Larry Radbill, MA; \\ Paul L. Juneau, MS; Leslie Spangler, VMD, PhD; Faisal M. Mirza, MD; and Bradley S. Stolshek, PharmD
}

\begin{abstract}
BACKGROUND: Prior research has shown that rates of persistence and compliance with osteoporosis therapies are associated with significantly fewer vertebral, nonvertebral, and hip fractures. A number of studies have examined medication-taking behavior with oral bisphosphonates and teriparatide, and these 1-year persistence rates have ranged from $39.9 \%$ to $56.7 \%$. Limited real-world data are available regarding persistence and compliance rates with newer therapies such as denosumab, a RANK ligand inhibitor administered every 6 months as a subcutaneous injection.
\end{abstract}

OBJECTIVE: To assess persistence and compliance rates over 1 year with newly initiated osteoporosis therapies, including denosumab, alendronate, ibandronate, risedronate, raloxifene, and teriparatide, within a cohort of commercially insured women.

METHODS: Health insurance claims data derived from Truven Health Analytics MarketScan Commercial Claims and Encounters and Medicare Supplemental and Coordination of Benefits databases (2010-2013) were used to conduct this retrospective cohort study. Adult females aged 18 years and older newly initiated on denosumab, raloxifene, teriparatide, or oral bisphosphonates (alendronate, ibandronate, or risedronate) between January 1, 2012, and March 31, 2012, were identified for inclusion. The date of the first qualifying osteoporosis prescription claim was defined as the index date. Patients were required to have at least 24 months of pre-index and at least 12 months of post-index continuous enrollment with medical and pharmacy benefits. Outcomes of patients initiating zoledronic acid (administered intravenously once yearly) were not assessed because a 12-month follow-up period would be insufficient for tracking persistence and compliance for this medication. Patients with Paget's disease of the bone, osteogenesis imperfecta, hypercalcemia, malignant cancer and metastasis, human immunodeficiency virus, and patients receiving preventive treatment for risk of breast cancer or denosumab in the pre-index period were excluded from the study. A subcohort of women aged 50 years and older at high risk for fracture (indicated by 1 or more of the following: aged $\geq 70$ years, a pre-index fracture, or pre-index use of osteoporosis therapy that was discontinued at least 3 months prior to index) was analyzed separately. Propensity score weighting was used to adjust for differences in baseline demographic and clinical characteristics. Persistence, indicated by continuous use of the index therapy without a gap of 60 days or more; medication coverage ratio (MCR), the proportion of days covered by the index therapy; and compliance, defined as an MCR $\geq 0.80$, were assessed during the 12-month follow-up. Logistic regression was used to estimate the odds of persistence and compliance for the treatment groups of interest.

RESULTS: 10,863 female patients newly initiating osteoporosis medications (mean [SD] age: 66.2 [11.5] years) were identified. In the pre-index period, $35.8 \%$ of patients had a diagnosis of osteoporosis, while $11.5 \%$ had a diagnosis of osteopenia. Pre-index osteoporosis treatment was identified in $29.1 \%$ of patients, and $13.6 \%$ had an osteoporosis-related fracture in the pre-index period. Propensity score weight-adjusted 12-month persistence with the index medication varied from $28.9 \%$ to $35.1 \%$ for oral bisphosphonate users, $42.0 \%$ for raloxifene users, $59.1 \%$ for teriparatide users, and $68.3 \%$ for denosumab users $(P<0.0001)$. The adjusted mean [SD] MCR was highest among patients treated with denosumab $(0.83[0.21])$, followed by teriparatide $(0.67$ [0.31]), raloxifene, $(0.57$ [0.34]), ibandronate $(0.54$ [0.32]), alendronate $(0.51$ [0.33]), and risedronate $(0.46$ [0.33]; $P<0.0001)$. The odds of being persistent and compliant across treatments favored denosumab ( $\mathrm{OR}=1.59$ to $5.56, P<0.05$ for persistence; $\mathrm{OR}=2.44$ to $7.69, P<0.0001$ for compliance). Results were similar in the subcohort of women aged 50 years and older at high risk for fracture $(n=6,187$; mean [SD] age: 71.9 [10.9] years). The odds of being persistent and compliant across treatments also favored denosumab $(0 R=1.62$ to $5.75, P<0.0001$ for persistence; $\mathrm{OR}=2.36$ to $7.25, P<0.0001$ for compliance).

CONCLUSIONS: In a U.S. setting, rates of persistence and compliance over 12 months were higher among women initiating denosumab compared with those initiating other osteoporosis therapies.

J Manag Care Spec Pharm. 2015;21(9):824-33

Copyright $\odot 2015$, Academy of Managed Care Pharmacy. All rights reserved.

\section{What is already known about this subject}

Persistence and compliance with osteoporosis therapies is associated with significantly fewer vertebral, nonvertebral, and hip fractures.

A number of studies have examined persistence with oral bisphosphonates and teriparatide, and 1-year persistence rates have ranged from $39.9 \%$ to $56.7 \%$.

Limited real-world data are available regarding persistence and compliance with newer osteoporosis therapies, such as denosumab, a RANK ligand inhibitor administered every 6 months as a subcutaneous injection.

\section{What this study adds}

This U.S.-based, retrospective, observational cohort study assessed persistence and compliance among women diagnosed with osteoporosis following initiation of osteoporosis medications including denosumab, alendronate, ibandronate, risedronate, raloxifene, and teriparatide.

Results show that rates of real-world persistence and compliance with osteoporosis therapies vary considerably across therapies.

Patients receiving treatment with denosumab had considerably higher rates of persistence and compliance compared with patients treated with other therapies. 
$\mathrm{O}$ steoporosis is a chronic, systemic condition characterized by low bone mass and deterioration of bone tissue that increases the risk for fracture. ${ }^{1}$ The lifetime risk of osteoporosis-related fractures is estimated to be $40 \%-50 \%$ in women diagnosed with osteoporosis. ${ }^{2}$ The goal of osteoporosis therapy is the prevention or reduction of bone fractures, which is accomplished by managing bone density. ${ }^{3}$

Current treatment options include bisphosphonates, selective estrogen receptor modulators (SERMs), recombinant parathyroid hormone analogues, and monoclonal antibody. Dosing schedules vary widely among available therapies: from once daily (e.g., bisphosphonates, raloxifene, and teriparatide), to once weekly (e.g., bisphosphonates), every 3 months (e.g., ibandronate), every 6 months (e.g., denosumab), or once yearly (e.g., zoledronic acid). A study of gaps in therapy among patients treated for osteoporosis found that of 40,002 newly treated patients from 1996 to 2002, 67\% had at least one 60-day period in which no days were covered by any osteoporosis medication. ${ }^{4}$ Within 1 year of treatment initiation, approximately half of patients taking oral therapies discontinue treatment. 5,6 It is apparent, then, that there is a need to improve continued use of early osteoporosis therapy.

The Medication Adherence and Persistence Special Interest Working Group of the International Society for Pharmacoeconomics and Outcomes Research defines medication persistence as "the duration of time from initiation to discontinuation of treatment" and defines adherence or compliance as "the extent to which a patient acts in accordance with the prescribed interval, and dose of a dosing regimen." Previous research has shown that persistence and compliance with osteoporosis therapy are suboptimal despite the fact that better persistence and compliance are associated with significantly fewer fractures..$^{8-10}$ A systematic review of 17 publications examining compliance and persistence data from retrospective/observational studies found that low compliance and persistence rates are associated with higher rates of fracture. ${ }^{11}$ While most available osteoporosis therapies are generally well tolerated, potential adverse effects may limit use of some medications. For example, gastrointestinal adverse effects are a commonly cited reason for bisphosphonate discontinuation. ${ }^{12}$ Other factors potentially associated with nonpersistence include frequent dosing (e.g., daily or weekly dosing), younger age, and concomitant medication use. ${ }^{13}$

In recent years, new osteoporosis therapies have become available with less frequent oral dosing administration; however, real-world persistence and compliance data for these therapies are limited. Dosing frequency has been associated with improved compliance and persistence with oral weekly and monthly bisphosphonate therapy; yet, frequent dosing has been cited as a reason in osteoporosis patients for nonpersistence. ${ }^{14}$ In a study comparing compliance and persistence, weekly alendronate users showed significantly higher medication compliance than did daily users. Moreover, weekly users persisted with therapy significantly longer than daily users. ${ }^{15}$ Other studies found that a once-monthly dosing regimen of oral bisphosphonates was associated with less adherence failure and improved persistence rates compared with once-daily or once-weekly administration of bisphosphonate therapy. ${ }^{16,17}$ Together, these studies suggest that reduced dosing frequency may play an important role in improving adherence and persistence with therapy among osteoporotic patients.

In a 2-year randomized crossover study, postmenopausal women with osteoporosis were more persistent and compliant when treated every 6 months with subcutaneous denosumab than with once-weekly alendronate tablets. ${ }^{18,19} \mathrm{~A}$ recent prospective, multicenter, observational study examining persistence with denosumab in routine community practice in the United States and Canada found $80 \%$ persistence at 12 months. ${ }^{20}$ While these studies suggest that denosumab may be associated with improved persistence and compliance, gaps in the literature remain, especially evidence based on observational data from real-world clinical practice. In the present study, we seek to evaluate real-world persistence and compliance in osteoporotic women over a 12-month period following treatment initiation with osteoporosis therapies representing a range of dosing schedules.

\section{Methods}

\section{Data Source}

This retrospective study used data from the Truven Health Analytics MarketScan Commercial Claims and Encounters (Commercial) and the Medicare Supplemental and Coordination of Benefits (Medicare) databases for the period January 1, 2010, to March 31, 2013. The MarketScan databases include fully adjudicated medical and pharmacy claims for approximately 40 million individuals from over 160 large employers and health plans across the United States in 2010. Major data contributors include employers and health plans that cover employees and their dependents through a variety of insurance plan structures including fee-for-service (FFS), fully capitated, and partially capitated health plans that include preferred provider organizations (PPOs) and health maintenance organizations (HMOs). Medical claims are linked to outpatient prescription drug claims and person-level enrollment data through the use of unique enrollee identifiers. The Medicare database contains data reflecting the health care experiences of individuals with Medicare supplemental insurance paid for by employers and is representative of the national population of retirees with both Medicare and supplemental employer-sponsored health coverage. Both databases provide detailed cost, utilization, and outcomes data for health care services performed in inpatient and outpatient settings. The patient data used in this analysis were de-identified in compliance with the Health Insurance Portability and Accountability Act regulations; therefore, the study was not subject to institutional review board approval. 


\section{Patient Selection}

Females aged 18 years and older with at least 1 new medical or prescription claim for denosumab, alendronate, ibandronate, risedronate, raloxifene, or teriparatide were eligible for inclusion in the study. The date of a patient's first claim for a newly initiated osteoporosis therapy of interest appearing between January 1, 2012, and March 31, 2012, was designated as the index date. All patients were required to have continuous medical and pharmacy benefit enrollment for at least 24 months prior to (pre-index) their index therapy claims and 12 months following (post-index) the index claims. Zoledronic acid was not part of the analysis because a 12-month follow-up period is insufficient for tracking its persistence and compliance due to its once-yearly regimen length. Patients treated with the index osteoporosis medication during the pre-index period were excluded (patients treated with a non-index osteoporosis medication were eligible for inclusion). Patients with a diagnosis of Paget's disease of the bone, other osteitis deformans and osteopathies, osteogenesis imperfecta, malignant cancer and metastasis, human immunodeficiency virus, hypercalcemia, preventive treatment for risk of breast cancer (i.e., a claim for raloxifene plus International Classification of Diseases, Ninth Revision, Clinical Modification [ICD-9-CM] codes V10.3, V16.3, or V84.01) in the pre-index period were excluded. Those with a diagnosis of cancer or metastasis prior to a medical claim for denosumab in the post-index period were also excluded, since it may be assumed that such patients were treated with denosumab for bone problems secondary to cancer rather than osteoporosis.

As a subgroup analysis, women aged 50 years and older at high risk for fracture were identified from our overall study population and analyzed separately. For this group, high fracture risk was indicated by 1 or more of 3 criteria: aged $\geq 70$ years, a pre-index fracture, or pre-index use of osteoporosis therapy that was discontinued at least 3 months prior to index.

\section{Measures}

Patient demographic characteristics as of the date of index were captured and included age, health plan type, geographic region, primary payer (commercial or Medicare supplemental), and urban residence. Clinical characteristics measured during the 24-month baseline period included the Deyo-Charlson Comorbidity Index (CCI) score (an aggregate measure of comorbidity using select diagnoses associated with chronic disease); number of unique outpatient medications prescribed; number of unique ICD-9-CM codes at the 3-digit level; and diagnosis of osteoporosis, osteopenia, renal insufficiency, gastrointestinal disorders, coronary heart disease, and osteoporosis-related fracture.

Persistence (measured as the proportion of patients who received the index therapy during the follow-up period without exceeding a gap of 60 days following the end of the days'

\section{FIGURE 1 Patient Selection}

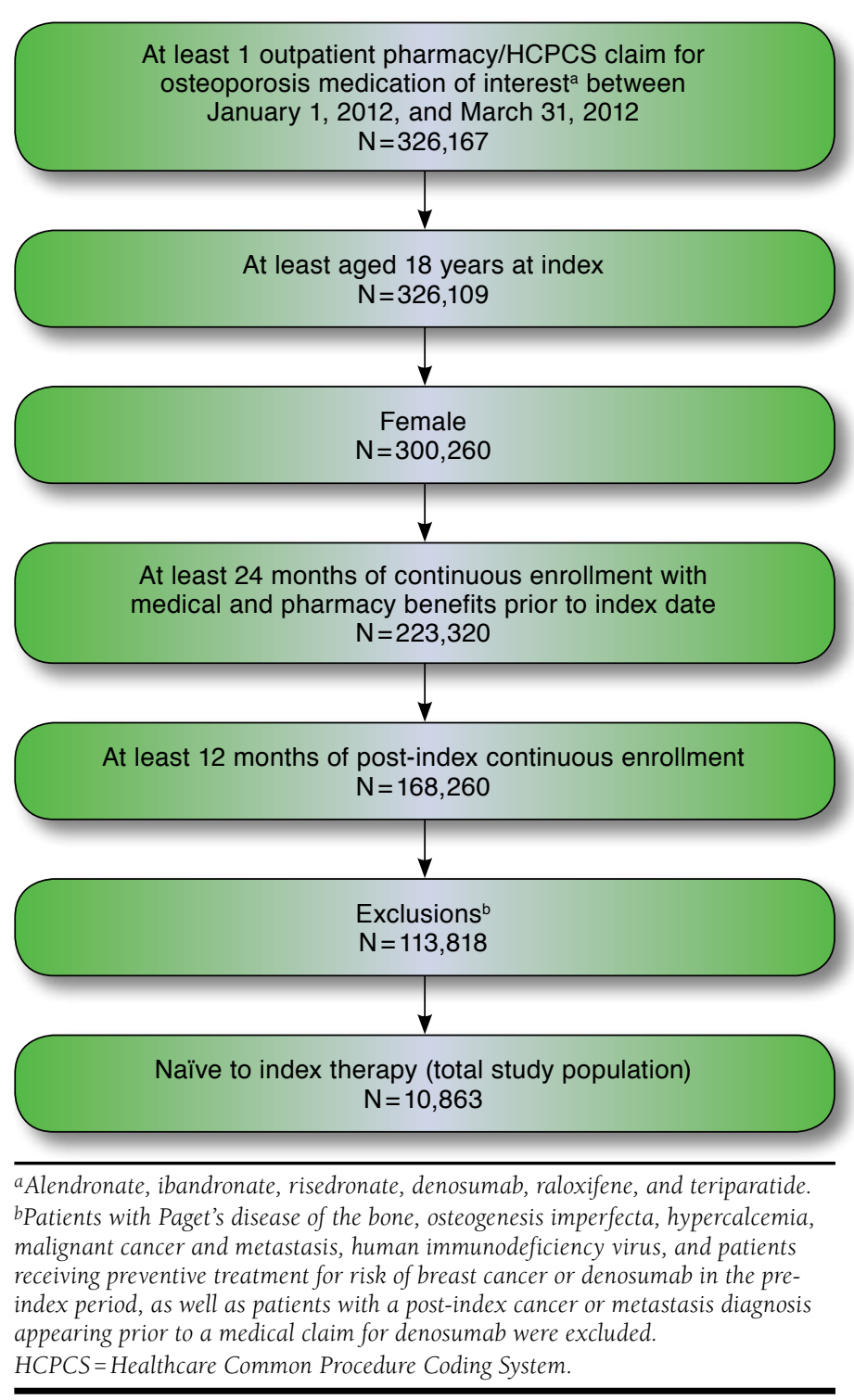

supply of the last observed claim for the index therapy $\left.{ }^{4}\right)$; medication coverage ratio (MCR; measured as the total days supplied from all refills of the index therapy during the follow-up period, divided by 365 days for each patient); and compliance (measured as the proportion of patients with an MCR $\geq 0.80$ ) were measured during the 12-month follow-up period. ${ }^{21,22}$ The first subsequent claims for denosumab appearing within 90 days of the index claim were excluded from the assessment of persistence and compliance outcomes to minimize the possibility of including potentially duplicate claims. The MCR is conceptually equivalent to the medication possession ratio (MPR) - both refer to the proportion of time patients have 
TABLE 1 Baseline Demographic Characteristics (Unweighted)

\begin{tabular}{|c|c|c|c|c|c|c|c|c|c|c|c|c|c|c|c|}
\hline \multirow[b]{2}{*}{ Mean age (SD) } & \multicolumn{2}{|c|}{$\begin{array}{l}\text { All Patients } \\
\mathrm{N}=10,863\end{array}$} & \multicolumn{2}{|c|}{$\begin{array}{c}\text { Denosumab } \\
n=1,235\end{array}$} & \multicolumn{2}{|c|}{$\begin{array}{c}\text { Alendronate } \\
n=5,458\end{array}$} & \multicolumn{2}{|c|}{$\begin{array}{c}\text { Ibandronate } \\
n=1,696\end{array}$} & \multicolumn{2}{|c|}{$\begin{array}{c}\text { Risedronate } \\
n=1,341\end{array}$} & \multicolumn{2}{|c|}{$\begin{array}{c}\text { Raloxifene } \\
\mathrm{n}=805\end{array}$} & \multicolumn{2}{|c|}{$\begin{array}{c}\text { Teriparatide } \\
\mathbf{n}=328\end{array}$} & \multirow{2}{*}{$\begin{array}{l}P_{\text {Value }} \text { a }^{<} \\
<0.0001\end{array}$} \\
\hline & 66.2 & $(11.5)$ & 70.1 & $(11.8)$ & 66.2 & (11.6) & 65.6 & (11.3) & 64.2 & (10.9) & 63.9 & $(9.5)$ & 68.1 & $(11.8)$ & \\
\hline \multicolumn{16}{|l|}{ Age group, $\mathrm{n}(\%)$} \\
\hline $18-54$ & 1,460 & (13.4) & 99 & $(8.0)$ & 763 & $(14.0)$ & 226 & $(13.3)$ & 225 & $(16.8)$ & 111 & (13.8) & 36 & $(11.0)$ & 0.444 \\
\hline $55-64$ & 4,399 & $(40.5)$ & 388 & $(31.4)$ & 2,159 & (39.6) & 723 & $(42.6)$ & 615 & $(45.9)$ & 404 & $(50.2)$ & 110 & (33.5) & $<0.0001$ \\
\hline $65-74$ & 2,192 & $(20.2)$ & 262 & $(21.2)$ & 1,120 & $(20.5)$ & 329 & $(19.4)$ & 243 & $(18.1)$ & 164 & (20.4) & 74 & $(22.6)$ & 0.261 \\
\hline $75-84$ & 1,953 & $(18.0)$ & 327 & $(26.5)$ & 958 & (17.6) & 306 & $(18.0)$ & 181 & $(13.5)$ & 103 & $(12.8)$ & 78 & $(23.8)$ & $<0.0001$ \\
\hline $85+$ & 859 & $(7.9)$ & 159 & (12.9) & 458 & $(8.4)$ & 112 & $(6.6)$ & 77 & $(5.7)$ & 23 & (2.9) & 30 & $(9.1)$ & $<0.0001$ \\
\hline Medicare, n (\%)b & 4,784 & $(44.0)$ & 729 & $(59.0)$ & 2,434 & $(44.6)$ & 707 & (41.7) & 478 & (35.6) & 269 & $(33.4)$ & 167 & $(50.9)$ & $<0.0001$ \\
\hline \multicolumn{16}{|l|}{ Health plan type, n (\%) } \\
\hline Comprehensive & 2,929 & $(27.0)$ & 421 & $(34.1)$ & 1,467 & $(26.9)$ & 508 & $(30.0)$ & 228 & $(17.0)$ & 187 & $(23.2)$ & 118 & $(36.0)$ & $<0.0001$ \\
\hline POS & 893 & $(8.2)$ & 94 & $(7.6)$ & 421 & $(7.7)$ & 162 & $(9.6)$ & 121 & $(9.0)$ & 69 & (8.6) & 26 & $(7.9)$ & 0.160 \\
\hline $\mathrm{HMO}$ & 1,549 & $(14.3)$ & 117 & $(9.5)$ & 957 & $(17.5)$ & 182 & $(10.7)$ & 176 & $(13.1)$ & 90 & $(11.2)$ & 27 & $(8.2)$ & $<0.0001$ \\
\hline $\mathrm{PPO}$ & 4,618 & $(42.5)$ & 530 & $(42.9)$ & 2,130 & $(39.0)$ & 738 & $(43.5)$ & 697 & $(52.0)$ & 388 & $(48.2)$ & 135 & $(41.2)$ & $<0.0001$ \\
\hline Other & 755 & $(7.0)$ & & $(4.9)$ & 426 & $(7.8)$ & 86 & $(5.1)$ & 101 & $(7.5)$ & 61 & $(7.6)$ & 20 & $(6.1)$ & 0.000 \\
\hline Unknown & 119 & (1.1) & 12 & $(1.0)$ & 57 & (1.0) & 20 & $(1.2)$ & 18 & (1.3) & 10 & $(1.2)$ & 2 & $(0.6)$ & 0.839 \\
\hline \multicolumn{16}{|l|}{ Geographic region, $\mathrm{n}(\%)$} \\
\hline Northeast & 1,595 & $(14.7)$ & 162 & $(13.1)$ & 736 & $(13.5)$ & 270 & $(15.9)$ & 259 & $(19.3)$ & 119 & $(14.8)$ & 49 & $(14.9)$ & $<0.0001$ \\
\hline North Central & 2,830 & $(26.1)$ & 308 & $(24.9)$ & 1,570 & $(28.8)$ & 402 & $(23.7)$ & 276 & $(20.6)$ & 193 & $(24.0)$ & 81 & $(24.7)$ & $<0.0001$ \\
\hline South & 4,102 & $(37.8)$ & 544 & $(44.0)$ & 1,855 & $(34.0)$ & 728 & $(42.9)$ & 521 & $(38.9)$ & 325 & $(40.4)$ & 129 & (39.3) & $<0.0001$ \\
\hline West & 2,309 & $(21.3)$ & 220 & $(17.8)$ & 1,285 & $(23.5)$ & 294 & (17.3) & 280 & $(20.9)$ & 161 & $(20.0)$ & 69 & $(21.0)$ & $<0.0001$ \\
\hline Unknown & 27 & $(0.2)$ & 1 & $(0.1)$ & 12 & $(0.2)$ & 2 & $(0.1)$ & 5 & $(0.4)$ & 7 & $(0.9)$ & 0 & $(0.0)$ & 0.005 \\
\hline Urban residence, n (\%) & 9,316 & $(85.8)$ & 1,036 & $(83.9)$ & 4,663 & $(85.4)$ & 1,459 & $(86.0)$ & 1,182 & $(88.1)$ & 700 & $(87.0)$ & 276 & $(84.1)$ & 0.043 \\
\hline
\end{tabular}

aP values calculated using $\chi 2$ tests for categorical variables and analysis of variance for continuous variables.

bVersus commercial.

$H M O=$ health maintenance organization; $P O S$ = point of service; $P P O=$ preferred provider organization; $S D=$ standard deviation .

access to a medication. However, because our study includes injectable medications that may be administered by health care professionals, we used MCR instead of MPR to describe the medication days "covered" during the follow-up period.

\section{Primary Statistical Analysis}

The different treatment cohorts were weighted by the propensity score to achieve balance in various patient demographic and clinical characteristics. Subsequent multivariable analyses were also propensity score weighted. ${ }^{23}$ The benefits of propensity score weighting versus matching have been discussed in the literature. ${ }^{24}$ Due to the number of treatment cohorts considered in the present study, the statistical optimality of weighting over matching was considered against the potential loss of patients that can occur in matching. Briefly, the propensity score weighting approach offered the benefit of conservation of size of the treatment cohorts, insofar as-in propensity score matching with nearest neighbor or with a caliper-it is possible that a patient in 1 treatment cohort might not be suitably matched with a patient in the comparator or reference group and, thus, is excluded from analysis. Moreover, an inconsistency with matching is possible. For instance, one patient in the comparator group might be suitably matched with a patient in another treatment group, whereas that same patient might not be suitably matched with a patient in a third, fourth, or fifth treatment group. This can then result in the composition of the comparator patient group varying as a function of the treatment used in the comparison.

Covariates included in the propensity score weighting model were age, health plan type, U.S. Census region, urban residency, payer (commercial or Medicare), and the following baseline clinical characteristics: CCI score; number of unique 3-digit ICD-9-CM codes; number of unique outpatient medications prescribed; number of unique osteoporosis medications prescribed; and diagnosis of osteoporosis, osteopenia, renal insufficiency, gastrointestinal disorders, and osteoporosisrelated fracture. All study measures were summarized using descriptive statistics. Categorical measures were presented as counts and percentages. Continuous measures were presented as means and standard deviations (SD). Chi-square tests and analysis of variance (ANOVA) were conducted to test the significance of differences between the treatment cohorts in study measures, with $P$ value $<0.05$ considered significant.

Logistic regression was used to estimate the weighted persistence and compliance outcomes. A priori, a set of model covariates were selected for their possible influence on the outcomes. The models adjusted for age, health plan type, U.S. Census region, urban residency, and the following baseline/ 
Persistance and Compliance with Osteroporosis Therapies

Among Women in a Commercially Insured Population in the United States

TABLE 2 Baseline Clinical Characteristics (Unweighted)

\begin{tabular}{|c|c|c|c|c|c|c|c|c|}
\hline & \begin{tabular}{|c|} 
All Patients \\
$\mathrm{N}=10,863$
\end{tabular} & $\begin{array}{c}\text { Denosumab } \\
\mathbf{n}=1,235\end{array}$ & $\begin{array}{c}\text { Alendronate } \\
\mathrm{n}=5,458\end{array}$ & $\begin{array}{c}\text { Ibandronate } \\
\mathrm{n}=1,696\end{array}$ & $\begin{array}{c}\text { Risedronate } \\
\mathrm{n}=1,341\end{array}$ & $\begin{array}{l}\text { Raloxifene } \\
\mathrm{n}=805\end{array}$ & $\begin{array}{l}\text { eriparatide } \\
\mathbf{n}=328\end{array}$ & $P$ Value $^{\mathrm{a}}$ \\
\hline CI, mean (SD) & $0.8 \quad(1.2)$ & (1.5) & $0.7 \quad(1.2)$ & $0.7 \quad(1.1)$ & $\begin{array}{ll}0.7 & (1.2)\end{array}$ & $0.6 \quad(1.1)$ & (1.3) & $<0.0001$ \\
\hline $\begin{array}{l}\text { umber of ICD-9-CM diagnoses, }{ }^{b} \\
\text { lean (SD) }\end{array}$ & $13.3 \quad(8.4)$ & $(9.3)$ & $2.0 \quad(7.8)$ & $14.3 \quad(8.5)$ & $13.4 \quad(8.0)$ & $12.8 \quad(7.6)$ & $18.5(10.6)$ & $<0.0001$ \\
\hline Number of unique NDCs, ${ }^{\mathrm{c}}$ mean (SD) & $16.4(21.7)$ & $19.4(13.9)$ & $15.7(12.1)$ & $16.8(12.9)$ & $15.9(12.4)$ & $14.0(11.3)$ & $22.0(16.3)$ & 001 \\
\hline Diagnosis of osteoporosis, n (\%) & $3,892(35.8)$ & $934(75.6)$ & $1,214(22.2)$ & $794(46.8)$ & $473(35.3)$ & $229(28.4)$ & $248(75.6)$ & $<0.0001$ \\
\hline Diagnosis of osteopenia & 1,251 (11.5) & $49 \quad(4.0)$ & $656(12.0)$ & 193 (11.4) & $218(16.3)$ & $124(15.4)$ & $11 \quad(3.4)$ & $<0$ \\
\hline Osteoporosis therapy, n (\%) & $3,166(29.1)$ & $675(54.7)$ & $1,185 \quad(21.7)$ & $469 \quad(27.7)$ & $443(33.0)$ & $235(29.2)$ & $159(48.5)$ & $<0.0001$ \\
\hline Osteoporosis-related fractu & 1,474 (13.6) & $208(16.8)$ & $708(13.0)$ & 197 (11.6) & $161(12.0)$ & $71 \quad(8.8)$ & $129(39.3)$ & $<0.0001$ \\
\hline Renal insufficiency, n (\%) & $431 \quad(4.0)$ & $86 \quad(7.0)$ & $216 \quad(4.0)$ & $47 \quad(2.8)$ & $46 \quad(3.4)$ & $19 \quad(2.4)$ & $17 \quad(5.2)$ & $<0.0001$ \\
\hline GI disorders, $\mathrm{n}(\%)$ & $4,205(38.7)$ & $574(46.5)$ & $1,887(34.6)$ & $716(42.2)$ & $553 \quad(41.2)$ & $309(38.4)$ & $166(50.6)$ & $<0.0001$ \\
\hline \multicolumn{9}{|c|}{$\begin{array}{l}\text { a values calculated using } \chi 2 \text { tests for categorical variables and analysis of variance for continuous variables across therapies. } \\
{ }^{2} \text { Number of unique ICD-9-CM diagnosis codes at the 3-digit level on medical claims. } \\
\text { cNumber of unique NDC numbers at the generic level from outpatient pharmacy claims. } \\
C C I=\text { Charlson Comorbidity Index; GI=gastrointestinal; ICD-9-CM=International Classification of Diseases, Ninth Revision, Clinical Modification; NDC=National } \\
\text { Drug Code; SD = standard deviation. }\end{array}$} \\
\hline
\end{tabular}

pre-index clinical characteristics: CCI score; number of unique outpatient medications prescribed; diagnosis of osteoporosis, osteopenia, renal insufficiency, gastrointestinal disorders, coronary heart disease, and osteoporosis-related fracture; copayment/coinsurance amount for the index therapy; and the index therapy. The nominal level of statistical significance for all tests was set at 0.05 .

\section{Sensitivity Analyses}

To evaluate the robustness of our primary results, we undertook a series of 2 sensitivity analyses. First, because the required period of continuous pre-index enrollment for our primary study population was rather lengthy ( 24 months), we replicated our analysis within a subcohort of patients with only 6 months of continuous pre-index enrollment (all remaining selection criteria from the primary analysis applied). Second, to evaluate whether our persistence results were sensitive to the duration of the allowable gap of 60 days, analyses using 30and 90-day gap allowances in the definition of persistence were also conducted. ${ }^{5,25}$ Coefficients from each model were plotted to assess agreement.

\section{Results}

\section{Patient Disposition}

A total of 326,167 patients were identified with at least 1 prescription or medical claim for an osteoporosis medication of interest (i.e., alendronate, ibandronate, risedronate, denosumab, raloxifene, and teriparatide) between January 1, 2012, and March 31, 2012. Of 326,167 patients newly initiated on alendronate, ibandronate, risedronate, denosumab, raloxifene, or teriparatide between January 1, 2012, and March 31, 2012, the final cohort that met the selection criteria consisted of 10,863 patients (Figure 1). Of these, 5,458 (50.2\%) patients were treated with alendronate; $1,696(15.6 \%)$ received ibandronate; $1,341(12.3 \%)$ received risedronate; 1,235 (11.4\%) received denosumab; and 805 (7.4\%) and 328 (3.0\%) patients were treated with raloxifene and teriparatide, respectively (Table 1 ).

\section{Demographic and Clinical Characteristics}

Table 1 presents the demographic characteristics of the study population by treatment cohort. The mean (SD) age of patients in the study population was 66.2 (11.5) years. Most patients (85.8\%) resided in an urban area, and $37.8 \%, 26.1 \%$, and $21.3 \%$ were from the South, North Central, and West U.S. Census regions, respectively. The majority of patients (56.0\%) were insured commercially, while the remainder had Medicare supplemental insurance (44.0\%). Overall, $42.5 \%$ of patients were enrolled in a PPO; $27.0 \%$ were enrolled in a comprehensive health plan; and $14.3 \%$ were enrolled in an HMO.

Table 2 displays the baseline clinical characteristics of the study population by treatment cohort. Slightly more than onethird (35.8\%) of the overall study population had a diagnosis of osteoporosis, while $11.5 \%$ had a diagnosis of osteopenia during the pre-index period. Overall, 29.1\% had evidence of osteoporosis therapy in the pre-index period, and $13.6 \%$ had evidence of a pre-index osteoporosis-related fracture. Propensity score-weighted demographic and clinical characteristics are displayed in Appendices A and B (available in online article). With the exceptions of health plan type and geographic region, the propensity score weighting procedure balanced the demographic and baseline clinical characteristics across treatment cohorts.

\section{Persistence and Compliance}

Propensity score weight-adjusted 12-month persistence and compliance rates are displayed in Figure 2. Within the overall 


\section{FIGURE 2 Propensity Score Weight Adjusted Rates of Persistence and Compliance} with Osteoporosis Therapies During 12-Month Follow-upa,b

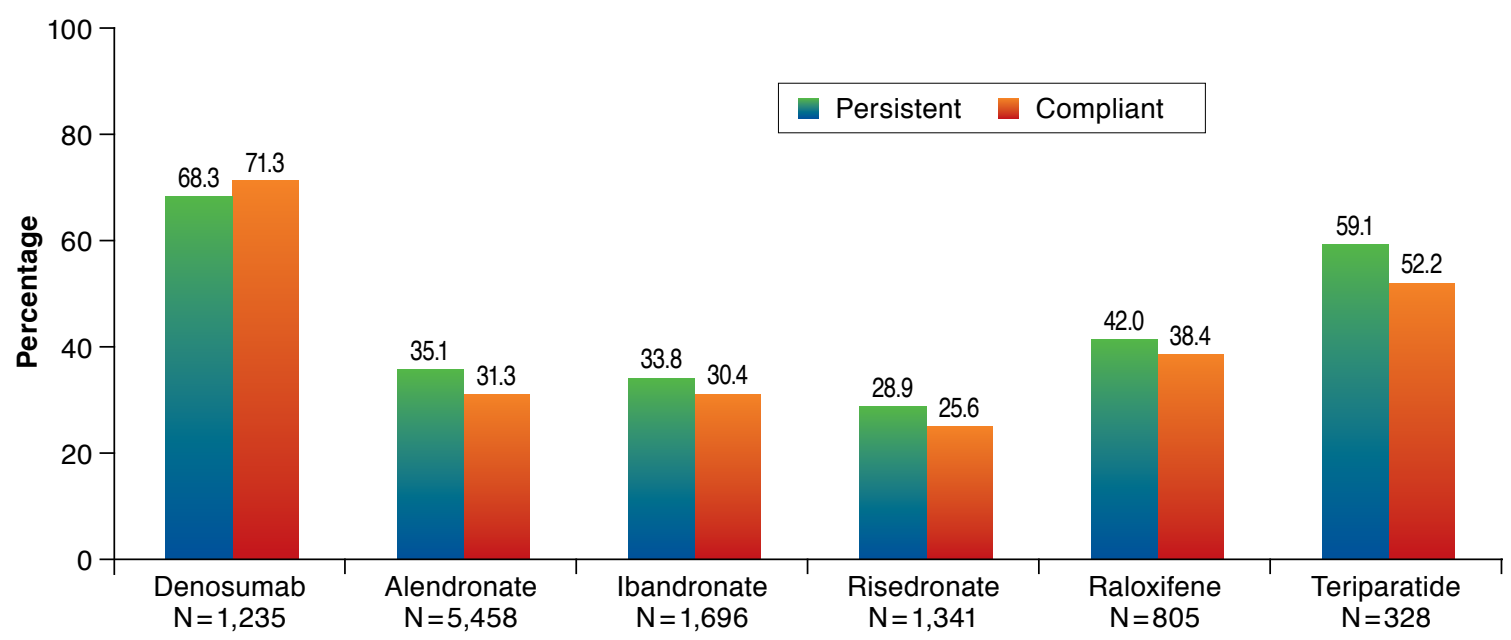

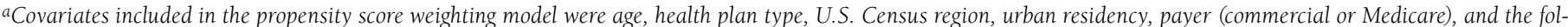

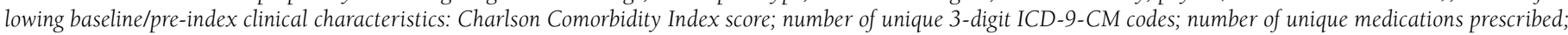
and diagnosis of osteoporosis, osteopenia, renal insufficiency, gastrointestinal side effects, and osteoporosis-related fracture.

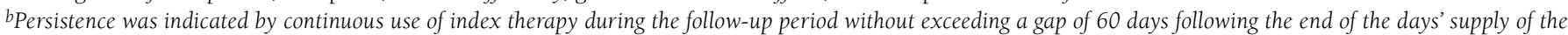

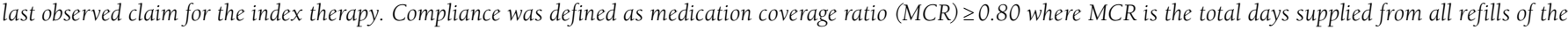
index therapy, divided by 365 days.

ICD-9-CM = International Classification of Diseases, Ninth Revision, Clinical Modification.

study population, 4,251 patients (39.1\%) were persistent, and 3,927 (36.2\%) patients were compliant with their index therapies. Propensity score weight-adjusted 12-month persistence with the index medication was highest among patients treated with denosumab (68.3\%), followed by teriparatide (59.1\%), raloxifene, (42.0\%), alendronate (35.1\%), ibandronate (33.8\%), and risedronate $(28.9 \% ; \mathrm{P}<0.0001)$. Similarly, the propensity score weight-adjusted 12-month compliance rate was highest among patients treated with denosumab (71.3\%), followed by teriparatide (52.2\%), raloxifene, (38.4\%), alendronate (31.3\%), ibandronate $(30.4 \%)$, and risedronate $(25.6 \% ; P<0.0001)$. As noted in the Methods section, first subsequent claims for denosumab appearing within 90 days of the index claim $(n=46)$ were not considered returns and thus were not included in the assessment of persistence and compliance outcomes.

Table 3 displays the propensity score weight-adjusted odds ratios (OR) and associated 95\% confidence intervals (CI) from the logistic regression models predicting persistence and compliance with the index therapies over the 12 months of follow-up. Patients newly treated with denosumab had significantly greater odds of being persistent $(O R=4.17 ; 95 \%$ $\mathrm{CI}=3.69-4.83 ; \quad P<0.0001)$ and compliant $(\mathrm{OR}=5.88 ; 95 \%$ $C I=5.10-6.71 ; P<0.0001)$ than those treated with alendronate. Denosumab users were also significantly more likely to be persistent $(\mathrm{OR}=4.55 ; 95 \% \mathrm{CI}=3.85-5.29 ; \mathrm{P}<0.0001)$ and compli- ant $(\mathrm{OR}=6.25 ; 95 \% \mathrm{CI}=5.21-7.25 ; \mathrm{P}<0.0001)$ compared with ibandronate users. This pattern of results was also observed for comparisons of denosumab patients with those treated with risedronate $(\mathrm{OR}=5.56 ; 95 \% \mathrm{CI}=4.78-6.76 ; \mathrm{P}<0.0001$ for persistence; $\mathrm{OR}=7.69 ; 95 \% \mathrm{CI}=6.54-9.26 ; \mathrm{P}<0.0001$ for compliance), raloxifene (OR=3.13; 95\% CI $=2.61-3.80 ; P<0.0001$ for persistence; $O R=4.35 ; 95 \% C I=3.52-5.15 ; P<0.0001$ for compliance), and teriparatide (OR $=1.59 ; 95 \% \mathrm{CI}=1.23-2.04$; $P<0.0001$ for persistence; $O R=2.44 ; 95 \% \quad C I=1.92-3.17$; $P<0.0001$ for compliance).

\section{Subgroup Analysis: Patients at High Risk for Fracture}

Patients at high risk for fracture included those aged 70 years and older $(n=3,840)$; those aged 50 years and older with a fracture during the pre-index period $(n=1,433)$; and those aged 50 years and older receiving osteoporosis therapy during the pre-index period that was discontinued at least 3 months prior to index $(n=3,347)$. Taken together, these criteria identified 6,187 unique patients for the high-risk subgroup analysis. The mean (SD) age of this subgroup was 71.9 (10.9) years. During the baseline period, $49.2 \%$ of these patients had an osteoporosis-related therapy, and $23.2 \%$ had an osteoporosisrelated fracture (results not shown in tabular form). Figure 3 displays the propensity score weight-adjusted 12-month persistence and compliance rates for this subgroup. As shown in 


\begin{tabular}{|c|c|c|c|c|c|c|}
\hline \multirow[t]{3}{*}{ TABLE 3} & $\begin{array}{l}\text { core Weig } \\
\text { nd Comp }\end{array}$ & $\begin{array}{l}\text { usted C } \\
\text { Define }\end{array}$ & $\begin{array}{l}\text { Associa } \\
60-D\end{array}$ & $\begin{array}{l}\% \text { Cls fron } \\
\text { Allowanc }\end{array}$ & $\begin{array}{l}\text { tic Rec } \\
\text { Index }\end{array}$ & $\begin{array}{l}\text { Models, } \\
\text { over } 12\end{array}$ \\
\hline & \multirow{2}{*}{$\begin{array}{c}\text { Persistence } \\
\text { OR }\end{array}$} & \multicolumn{2}{|c|}{$95 \% \mathrm{CI}$} & \multirow{2}{*}{$\begin{array}{c}\text { Compliance } \\
\text { OR }\end{array}$} & \multicolumn{2}{|c|}{$95 \%$ CI } \\
\hline & & Lower & Upper & & Lower & Upper \\
\hline Denosumab vs. alendronate & 4.17 & 3.69 & 4.83 & 5.88 & 5.10 & 6.71 \\
\hline Denosumab vs. ibandronate & 4.55 & 3.85 & 5.29 & 6.25 & 5.21 & 7.25 \\
\hline Denosumab vs. risedronate & 5.56 & 4.78 & 6.76 & 7.69 & 6.54 & 9.26 \\
\hline Denosumab vs. raloxifene & 3.13 & 2.61 & 3.80 & 4.35 & 3.52 & 5.15 \\
\hline Denosumab vs. teriparatide & 1.59 & 1.23 & 2.04 & 2.44 & 1.92 & 3.17 \\
\hline \multicolumn{7}{|c|}{$\begin{array}{l}\text { a Models adjusted for age, health plan type, U.S. Census region, urban residency, patient out-of-pocket expenditure for the index therapy, and the following baseline/pre- } \\
\text { index clinical characteristics: Charlson Comorbidity Index score; number of unique medications prescribed; and diagnosis of osteoporosis, osteopenia, renal insufficiency, } \\
\text { gastrointestinal disorders, coronary heart disease, and osteoporosis-related fracture. } \\
C I=\text { confidence interval; OR=odds ratio. }\end{array}$} \\
\hline
\end{tabular}

Figure 3, persistence with the index medication was highest among patients treated with denosumab (68.8\%), followed by teriparatide (58.3\%), raloxifene, (43.0\%), alendronate (36.0\%), ibandronate (33.4\%), and risedronate (28.0\%). The adjusted compliance rate varied from $70.2 \%$ for denosumab users, $51.1 \%$ for teriparatide users, $40.4 \%$ for raloxifene users, to 25.0\%-32.8\% for oral bisphosphonate users. The odds of being persistent and compliant across treatments favored denosumab (for persistence $\mathrm{OR}=1.62$ to $5.75, P<0.0001$; for compliance $\mathrm{OR}=2.36$ to $7.25, \mathrm{P}<0.0001)$.

\section{Sensitivity Analyses}

As previously noted, sensitivity analyses were conducted around the 24-month pre-index continuous enrollment requirement; analyses were also conducted with patients with 6 months of continuous pre-index enrollment. Further, sensitivity analyses using 30- and 90-day gap allowances in the definition of persistence were conducted. Coefficients from each model were plotted to assess agreement. Parameter estimates from the models based on the cohort with 6 months of continuous pre-index enrollment were in agreement with those from the cohort with 24 months of continuous pre-index enrollment. Parameter estimates from models estimated using 30- and 90-day gap allowances in the persistence and compliance outcomes were also in agreement with those using a 60-day gap allowance (Table 4).

\section{Discussion}

This retrospective, observational cohort study based on realworld data showed considerable variation in persistence and compliance with osteoporosis therapy. Within this population of women initiating a new osteoporosis therapy, those receiving treatment with denosumab had considerably higher rates of persistence and compliance compared with patients treated with other therapies. The findings are similar in the subgroup of patients who were at high risk for fracture. Results from sensitivity analyses using a shorter baseline period and varying gap allowances in the assessment of persistence are also consistent with the findings of the primary analysis.

The high rates of persistence and compliance observed among patients treated with denosumab in the present U.S. study are slightly lower than those reported in studies from other countries. For example, in a prospective single-arm observational study of 935 patients in the United States $(n=632)$ and Canada $(n=303)$, more than $80 \%$ of denosumab recipients persisted with therapy at 12 months. ${ }^{20}$ In a study of treatment persistence in Swedish women initiating denosumab for postmenopausal osteoporosis, $83 \%$ of women were persistent at 12 months. ${ }^{26}$ This study shows that less than half of patients treated with oral therapies discontinue treatment within 1 year, a finding that is consistent with previous work. ${ }^{17}$ Taken together, these findings suggest that women receiving denosumab treatment for osteoporosis have significantly higher persistence and compliance rates compared with similar patients receiving other therapies used in clinical practice.

The economic burden of osteoporosis-related fractures in the United States is estimated to be approximately $\$ 20$ billion. ${ }^{27}$ Poor medication persistence is a primary explanation for suboptimal clinical benefit of therapy. ${ }^{11}$ Medication persistence is poor in many chronic conditions, including diabetes, hyperlipidemia, and osteoporosis. ${ }^{28}$ Logically, any measure that helps patients comply with treatment may improve the overall effectiveness of therapy. The advantage of denosumab may be attributed to improved tolerability, its simplified dosing schedule, and its route of administration and related requirement of administration by a health care professional, relative to other studied osteoporosis therapies.

For the nonbisphosphonate medications, effective prevention and management of osteoporosis requires consistent, long-term therapy, since the effects of the medications wane with discontinuation. ${ }^{29}$ In contrast, residual benefits of therapy may occur with the bisphosphonates following discontinuation. 


\section{FIGURE 3 Propensity Score Weight-Adjusted Rates of Persistence and Compliance with Osteoporosis Therapies} During 12-Month Follow-up, Women Aged 50 Years and Older at High Risk for Fracture ${ }^{\mathrm{a}, \mathrm{b}}$

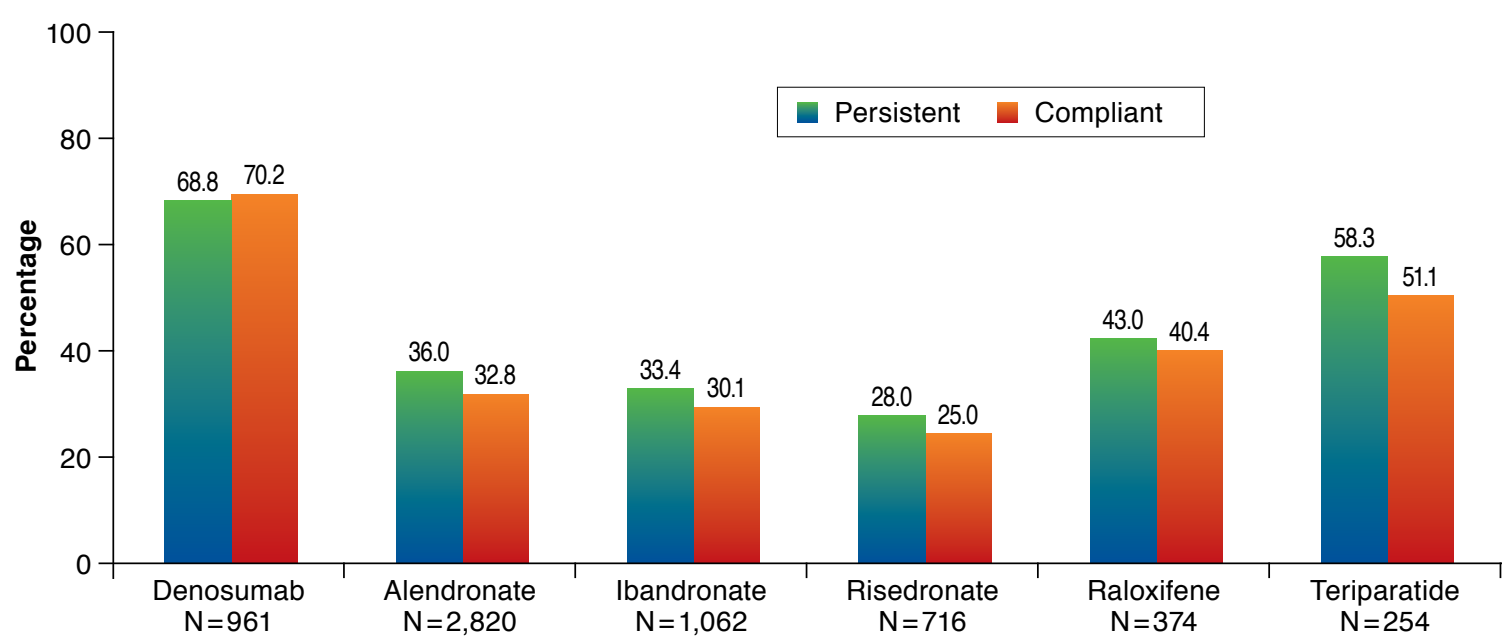

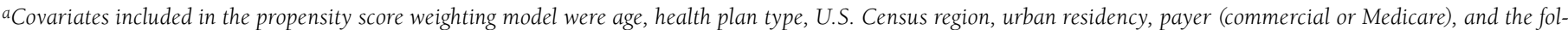

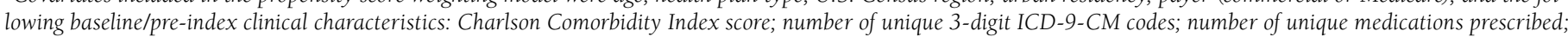
and diagnosis of osteoporosis, osteopenia, renal insufficiency, gastrointestinal side effects, and osteoporosis-related fracture.

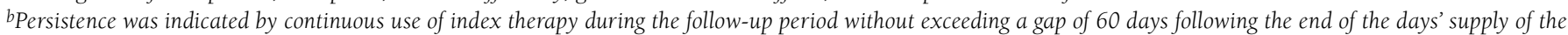

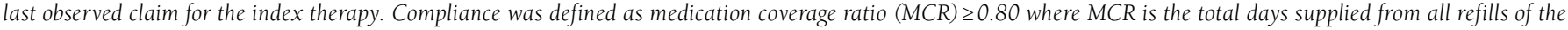
index therapy, divided by 365 days.

ICD-9-CM = International Classification of Diseases, Ninth Revision, Clinical Modification.

As such, drug holidays may be indicated for certain clinical scenarios (i.e., as indicated by T-score, risk factors, treatment length, and age) among patients treated with bisphosphonates. ${ }^{30}$

Improved persistence and compliance have been shown for denosumab relative to once-weekly alendronate. ${ }^{18,19}$ This study is the first to compare persistence and compliance of patients treated with denosumab to those treated with a range of medications currently prescribed for the treatment of osteoporosis in the U.S. setting. Injectable medications are generally under the supervision of health care professionals, which may lead to improved persistence and compliance. Optimal persistence and compliance may be harder to achieve with medications that have inconvenient and complicated dosing requirements or undesirable side effects. More convenient and simpler dosing schedules hold promise for improving persistence and compliance with osteoporosis therapies.

\section{Limitations}

The present study examined utilization of different osteoporosis therapies-it did not examine fracture outcomes or the costs associated with osteoporosis therapies. In addition, only patients newly initiating an osteoporosis therapy in the first quarter of 2012 were included. Also, because compliance is dependent upon the number of days of medication supplied, patients receiving 60- or 90-day supplies of their medications via mail order would have fewer opportunities for gaps in therapy than patients obtaining their medications through a retail pharmacy. Similarly, patients treated with medications with fewer doses during the 12-month follow-up also had fewer opportunities to exceed the permissible gap in therapy. That some medications are associated with fewer opportunities for gaps in therapy than others, however, does not reduce the value of examining compliance with therapies of different dosing frequencies. ${ }^{31,32}$

As with most health insurance claims-based retrospective studies, the present analysis is subject to several limitations that merit consideration. First, the data may be susceptible to selection bias and confounding factors. However, the propensity score weighting procedure did reduce the potential for confounding by achieving balance in most of the measured demographic and baseline clinical characteristics across the treatment cohorts. Second, the analyses were conducted using health care claims data, which are collected for billing rather than for research purposes and are subject to data coding limitations and data entry error. Third, persistence with therapy was estimated using outpatient pharmacy and/or medical claims adjudicated during the study period. While office-administered medications reflect the receipt of therapy, it cannot be assumed that medications obtained in the outpatient pharmacy setting were taken as prescribed. Additionally, data do not capture prescriptions written but not filled. Fourth, due to the length of follow-up, this analysis did not include 
TABLE 4 Propensity Score Weight-Adjusted ORs and Associated 95\% Cls from Logistic Regression Models, ${ }^{2}$ Persistence (Defined with 30- and 90-Day Gap Allowances) with Index Therapy over 12 Months

\begin{tabular}{|c|c|c|c|c|c|c|}
\hline & \multirow{2}{*}{$\begin{array}{c}\text { Persistence } \\
\text { (30-Day Gap } \\
\text { Allowance) } \\
\text { OR }\end{array}$} & \multicolumn{2}{|c|}{$95 \%$ CI } & \multirow{2}{*}{$\begin{array}{c}\text { Persistence } \\
\text { (90-Day Gap } \\
\text { Allowance) } \\
\text { OR }\end{array}$} & \multicolumn{2}{|c|}{$95 \% \mathrm{CI}$} \\
\hline & & Lower & Upper & & Lower & Upper \\
\hline Denosumab vs. alendronate & 5.10 & 4.48 & 5.85 & 4.00 & 3.48 & 4.61 \\
\hline Denosumab vs. ibandronate & 5.68 & 4.81 & 6.67 & 3.82 & 3.25 & 4.48 \\
\hline Denosumab vs. risedronate & 6.67 & 5.56 & 7.94 & 5.32 & 4.48 & 6.33 \\
\hline Denosumab vs. raloxifene & 3.18 & 2.64 & 3.85 & 2.87 & 2.37 & 3.46 \\
\hline Denosumab vs. teriparatide & 1.83 & 1.43 & 2.35 & 1.15 & 1.16 & 1.96 \\
\hline
\end{tabular}

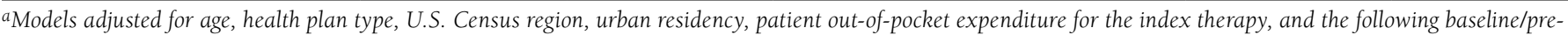

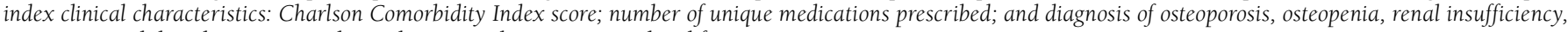
gastrointestinal disorders, coronary heart disease, and osteoporosis-related fracture.

$C I=$ confidence interval; $O R=$ odds ratio.

zoledronic acid. Finally, this analysis is limited to patients with commercial and Medicare supplemental insurance in the United States, so the results may not be representative of all patients with osteoporosis, such as those who are uninsured, self-insured, or covered by Medicaid.

\section{Conclusions}

Within this U.S.-based female study population, persistence and compliance over 12 months were higher among patients initiating denosumab compared with those initiating other osteoporosis therapies. Persistence with oral therapies is generally poor, and this study adds to the literature. This is the first U.S.-based study to compare persistence and compliance across a range of available osteoporosis therapies. Medications with less frequent dosing schedules and improved ability to monitor administration such as denosumab may improve persistence and compliance, thereby improving clinical and economic outcomes for patients with osteoporosis.

\section{Authors}

LUNG-I CHENG, PhD, is Senior Manager, Global Health Economics; BRADLEY S. STOLSHEK, PharmD, is Director, Global Health Economics; and LESLIE SPANGLER, VMD, PhD, is Senior Manager, Center for Observational Research, Amgen, Thousand Oaks, California. EMILY DURDEN, PhD, is Research Leader, Life Sciences; BRENDAN LIMONE, PharmD, is Analyst Manager, Life Sciences; and PAUL L. JUNEAU, MS, is Senior Statistician, Statistical Services Group, Truven Health Analytics, Bethesda, Maryland. LARRY RADBILL, MA, is Survey Statistician, NORC at the University of Chicago, Illinois, and FAISAL M. MIRZA, MD, is President, OrthoSynthesis, Los Gatos, California.

AUTHOR CORRESPONDENCE: Lung-I Cheng, PhD, One Amgen Center Dr., Mail Stop 28-3-A, Thousand Oaks, CA 91320-1799. Tel.: 805.447.2961; Fax: 805.376.1816; E-mail: lungic@amgen.com.

\section{DISCLOSURES}

This study was funded by Amgen and conducted by Truven Health Analytics, Bethesda, MD. Durden, Limone, and Juneau are employees, and Radbill was an employee, of Truven Health Analytics, who were paid by Amgen in connection with the conduct of this study and development of the manuscript. Cheng, Spangler, and Stolshek are employees, and Mirza was an employee, of Amgen.

Study concept and design were contributed by Cheng, Stolshek, and Durden, with assistance from Radbill, Juneau, and Spangler. Durden and Radbill collected the data, which were interpreted by Cheng, Durden, Juneau, and Mirza. The manuscript was written by Durden, Limone, and Cheng, with assistance from Juneau, and revised by Cheng, Spangler, Durden, and Limone, with assistance from Stolshek.

\section{ACKNOWLEDGMENTS}

Editorial support for this manuscript was provided by Santosh Tiwari who was compensated by Truven Health Analytics.

\section{REFERENCES}

1. NIH Consensus Development Panel on Osteoporosis Prevention, Diagnosis, and Therapy. Osteoporosis prevention, diagnosis, and therapy. JAMA. 2001;285(6):785-95. Available at: http://jama.jamanetwork.com/ article.aspx?articleid=193534. Accessed August 8, 2015.

2. Johnell O, Kanis J. Epidemiology of osteoporotic fractures. Osteoporos Int. 2005;16(Suppl 2):S3-S7.

3. Cummings SR, Melton LJ. Epidemiology and outcomes of osteoporotic fractures. Lancet. 2002;359(9319):1761-67. Available at: http://www.thelancet.com/journals/lancet/article/PIIS0140-6736(02)08657-9/fulltext. Accessed August 8, 2015

4. Brookhart MA, Avorn J, Katz JN, et al. Gaps in treatment among users of osteoporosis medications: the dynamics of noncompliance. Am J Med. 2007;120(3):251-56.

5. Weycker D, Macarios D, Edelsberg J, Oster G. Compliance with drug therapy for postmenopausal osteoporosis. Osteoporos Int. 2006;17(11):1645-52.

6. Cotté FE, Fardellone P, Mercier F, Gaudin AF, Roux C. Adherence to monthly and weekly oral bisphosphonates in women with osteoporosis Osteoporos Int. 2010;21(1):145-55

7. Cramer JA, Roy A, Burrell A, et al. Medication compliance and persistence: terminology and definitions. Value Health. 2008;11(1):44-47.

8. Seeman E, Compston J, Adachi J, et al. Non-compliance: the Achilles' heel of anti-fracture efficacy. Osteoporos Int. 2007;18(6):711-19. 
9. Foster SA, Foley KA, Meadows ES, et al. Adherence and persistence with teriparatide among patients with commercial, Medicare, and Medicaid insurance. Osteoporos Int. 2011;22(2):551-57.

10. Wade SW, Curtis JR, Yu J, et al. Medication adherence and fracture risk among patients on bisphosphonate therapy in a large United States health plan. Bone. 2012;50(4):870-75

11. Siris ES, Selby PL, Saag KG, Borgström F, Herings RM, Silverman SL. Impact of osteoporosis treatment adherence on fracture rates in North America and Europe. Am J Med. 2009;122(2 Suppl):S3-S13.

12. Kennel KA, Drake MT. Adverse effects of bisphosphonates: implications for osteoporosis management. Mayo Clin Proc. 2009;84(7):632-38. Available at: http://www.ncbi.nlm.nih.gov/pmc/articles/PMC2704135/. Accessed August 8, 2015

13. van Boven JF, de Boer PT, Postma MJ, Vegter S. Persistence with osteoporosis medications among newly treated osteoporotic patients. J Bone Miner Metab. 2013;31(5):562-70.

14. Carr AJ, Thompson PW, Cooper C. Factors associated with adherence and persistence to bisphosphonate therapy in osteoporosis: a cross-sectional survey. Osteoporos Int. 2006;17(11):1638-44.

15. Cramer JA, Amonkar MM, Hebborn A, Altman R. Compliance and persistence with bisphosphonate dosing regimens among women with postmenopausal osteoporosis. Curr Med Res Opin. 2005;21(9):1453-60. Available at: http://informahealthcare.com/doi/abs/10.1185/030079905X61875. Accessed August 8, 2015.

16. Briesacher BA, Andrade SE, Harrold LR, Fouayzi H, Yood RA. Adherence and occurrence of fractures after switching to once-monthly oral bisphophonates. Pharmacoepidemiol Drug Saf. 2010;19(12):1233-40. Available at: http://www.ncbi.nlm.nih.gov/pmc/articles/PMC3079953/. Accessed August 8, 2015

17. Confavreux CB, Canoui-Poitrine F, Schott AM, Ambrosi V, Tainturier V, Chapurlat RD. Persistence at 1 year of oral antiosteoporotic drugs: a prospective study in a comprehensive health insurance database. Eur J Endocrinol. 2012;166(4):735-41. Available at: http://eje-online.org/content/166/4/735.long. Accessed August 8, 2015.

18. Freemantle N, Satram-Hoang S, Tang ET, et al. Final results of the DAPS (Denosumab Adherence Preference Satisfaction) study: a 24-month, randomized, crossover comparison with alendronate in postmenopausal women. Osteoporos Int. 2012;23(1):317-26.

19. Kendler DL, McClung MR, Freemantle N, et al. Adherence, preference, and satisfaction of postmenopausal women taking denosumab or alendronate. Osteoporos Int. 2011;22(6):1725-35.

20. Silverman S, Siris E, Kendler DL, et al. Persistence at 12 months with denosumab in postmenopausal women with osteoporosis: interim results from a prospective observational study. Osteoporos Int. 2015;26(1):361-72.

21. Ziller V, Zimmermann SP, Kalder M, et al. Adherence and persistence in patients with severe osteoporosis treated with teriparatide. Curr Med Res Opin. 2010;26(3):675-81. Available at: http://informahealthcare.com/doi/ abs/10.1185/03007990903538409. Accessed August 8, 2015.
22. Ziller V, Wetzel K, Kyvernitakis I, Seker-Pektas B, Hadji P. Adherence and persistence in patients with postmenopausal osteoporosis treated with raloxifene. Climacteric. 2011;14(2):228-35. Available at: http://informahealthcare.com/doi/abs/10.3109/13697137.2010.514628. Accessed August 8, 2015.

23. Austin PC. An introduction to propensity score methods for reducing the effects of confounding in observational studies. Multivar Behav Res. 2011;46(3):399-424. Available at: http://www.ncbi.nlm.nih.gov/pmc/articles/ PMC3144483\%. Accessed August 8, 2015.

24. Kurth T, Alexander MW, Glynn RJ, et al. Results of multivariable logistic regression, propensity matching, propensity adjustment, and propensity weighting under conditions of nonuniform treatment effect. Amer J Epid. 2006;163(3):262-70.

25. Cooper A, Drake J, Brankin E. Treatment persistence with once-monthly ibandronate and patient support vs. once-weekly alendronate: results from the PERSIST study. Int J Clin Pract. 2006;60(8):896-905.

26. Karlsson L, Lundkvist J, Intorcia M, et al. Treatment persistence in Swedish women initiating denosumab treatment for post-menopausal osteoporosis. Poster presented at: 16th Annual European Congress of the International Society for Pharmacoeconomics and Outcomes Research 2013; November 2-6, 2013; Dublin, Ireland. [Abstract PMS72] Available at: http:// www.valueinhealthjournal.com/article/S1098-3015\%2813\%2903420-7/fulltext. Accessed August 8, 2015.

27. Burge R, Dawson-Hughes B, Solomon DH, Wong JB, King A, Tosteson A. Incidence and economic burden of osteoporosis-related fractures in the United States, 2005-2025. J Bone Miner Res. 2007;22(3):465-75.

28. Yeaw J, Benner JS, Walt JG, Sian S, Smith DB. Comparing adherence and persistence across 6 chronic medication classes. J Manag Care Pharm. 2009;15(9):728-40. Available at: http://www.amcp.org/data/jmcp/728-740.pdf

29. National Osteoporosis Foundation. 2014 Clinician's guide to prevention and treatment of osteoporosis. Washington, DC: National Osteoporosis Foundation; 2014. Available at: http://nof.org/files/nof/public/content/ file/2791/upload/919.pdf. Accessed August 8, 2015.

30. Diab DL, Watts NB. Bisphosphonate drug holiday: who, when and how long. Ther Adv Musculoskelet Dis. 2013;5(3):107-11. Available at: http://www ncbi.nlm.nih.gov/pmc/articles/PMC3707342/. Accessed August 8, 2015.

31. Feldman SR, Zhao Y, Navaratnam P, Friedman HS, Lu J, Tran MH. Patterns of medication utilization and costs associated with the use of etanercept, adalimumab, and ustekinumab in the management of moderate-tosevere psoriasis. J Manag Care Spec Pharm. 2015;21(3):201-09. Available at: http://www.amcp.org/JMCP/2015/March/19110/1033.html.

32. Martin KE, Yu J, Campbell HE, Abarca J, White TJ. Analysis of the comparative effectiveness of 3 oral bisphosphonates in a large managed care organization: adherence, fracture rates, and all-cause cost. J Manag Care Pharm. 2011;17(8):596-609. Available at: http://www.amcp.org/JMCP/2011/ October/12813/1033.html. 
Persistance and Compliance with Osteroporosis Therapies

Among Women in a Commercially Insured Population in the United States

APPENDIX A Baseline Demographic Characteristics (Weighted)

\begin{tabular}{|c|c|c|c|c|c|c|c|c|}
\hline & $\begin{array}{c}\text { All Patients } \\
\mathrm{N}=10,863\end{array}$ & $\begin{array}{c}\text { Denosumab } \\
\mathrm{n}=1,235\end{array}$ & $\begin{array}{c}\text { Alendronate } \\
\mathrm{n}=5,458\end{array}$ & $\begin{array}{c}\text { Ibandronate } \\
n=1,696\end{array}$ & $\begin{array}{c}\text { Risedronate } \\
n=1,341\end{array}$ & $\begin{array}{c}\text { Raloxifene } \\
\mathbf{n}=805\end{array}$ & $\begin{array}{c}\text { Teriparatide } \\
\mathbf{n}=328\end{array}$ & $P$ Value $^{\mathrm{a}}$ \\
\hline Mean age (SD) & $66.0 \quad(11.4)$ & $66.0 \quad(11.3)$ & $66.0 \quad(11.4)$ & $65.5 \quad(11.3)$ & $66.1 \quad(11.6)$ & $66.5 \quad(11.3)$ & $67.2(10.7)$ & 0.153 \\
\hline \multicolumn{9}{|l|}{ Age group, $\mathrm{n}(\%)$} \\
\hline $18-54$ & $1,478 \quad(12.0)$ & $166 \quad(11.8)$ & $742 \quad(12.0)$ & $247 \quad(12.7)$ & $189(12.4)$ & $101 \quad(11.2)$ & $34 \quad(9.3)$ & 0.374 \\
\hline $55-64$ & $4,455 \quad(41.0)$ & $496 \quad(40.2)$ & $2,247 \quad(41.2)$ & $716 \quad(42.2)$ & $549 \quad(40.9)$ & $323(40.1)$ & $125(38.0)$ & 0.714 \\
\hline $65-74$ & $2,198 \quad(20.2)$ & $272(22.0)$ & $1,098 \quad(20.1)$ & $334 \quad(19.7)$ & $258 \quad(19.2)$ & $162(20.1)$ & $75 \quad(22.9)$ & 0.407 \\
\hline $75-84$ & $1,916 \quad(17.6)$ & 205 (16.6) & $966 \quad(17.7)$ & $276 \quad(16.3)$ & $243(18.1)$ & 149 (18.6) & $77 \quad(23.4)$ & 0.045 \\
\hline $85+$ & $816 \quad(7.5)$ & $97 \quad(7.8)$ & $405 \quad(7.4)$ & $124 \quad(7.3)$ & $103 \quad(7.7)$ & $70 \quad(8.7)$ & $18 \quad(5.4)$ & 0.530 \\
\hline Medicare, $\mathrm{n}(\%)^{\mathrm{b}}$ & $4,714 \quad(43.4)$ & $539 \quad(43.6)$ & $2,367 \quad(43.4)$ & $701 \quad(41.3)$ & $577 \quad(43.0)$ & $365 \quad(45.4)$ & $164(50.1)$ & 0.067 \\
\hline \multicolumn{9}{|l|}{ Health plan type, n (\%) } \\
\hline Comprehensive & $2,978 \quad(27.4)$ & $338 \quad(27.4)$ & $1,493 \quad(27.4)$ & $442 \quad(26.1)$ & $354(26.4)$ & $222(27.6)$ & $128 \quad(39.1)$ & 0.000 \\
\hline POS & $908 \quad(8.4)$ & $105 \quad(8.5)$ & $456 \quad(8.3)$ & $142 \quad(8.4)$ & $113 \quad(8.4)$ & $65 \quad(8.1)$ & $28 \quad(8.5)$ & 1.000 \\
\hline $\mathrm{HMO}$ & $1,458 \quad(13.4)$ & $147 \quad(11.9)$ & $748 \quad(13.7)$ & $219 \quad(12.9)$ & $185(13.8)$ & $111 \quad(13.8)$ & $48 \quad(14.6)$ & 0.548 \\
\hline $\mathrm{PPO}$ & $4,652 \quad(42.8)$ & $551 \quad(44.6)$ & $2,322 \quad(42.6)$ & $746 \quad(44.0)$ & $578 \quad(43.1)$ & $344 \quad(42.7)$ & $111 \quad(33.8)$ & 0.017 \\
\hline Other & $744 \quad(6.8)$ & $85 \quad(6.9)$ & $378 \quad(6.9)$ & $122 \quad(7.2)$ & $96 \quad(7.2)$ & $51 \quad(6.3)$ & $12 \quad(3.8)$ & 0.327 \\
\hline Unknown & $123 \quad(1.1)$ & $9 \quad(0.7)$ & $61 \quad(1.1)$ & $25 \quad(1.5)$ & $14 \quad(1.1)$ & $13 \quad(1.6)$ & $(0.3)$ & 0.196 \\
\hline \multicolumn{9}{|l|}{ Geographic region, $\mathrm{n}(\%)$} \\
\hline Northeast & $1,635 \quad(15.0)$ & $190 \quad(15.4)$ & $791 \quad(14.5)$ & $248 \quad(14.6)$ & $210 \quad(15.7)$ & $121 \quad(15.0)$ & $75 \quad(22.8)$ & 0.004 \\
\hline North Central & $2,773 \quad(25.5)$ & $333(27.0)$ & $1,390 \quad(25.5)$ & $433(25.5)$ & $334(24.9)$ & $217 \quad(27.0)$ & $65 \quad(19.8)$ & 0.152 \\
\hline South & $4,176 \quad(38.4)$ & $457 \quad(37.0)$ & $2,129 \quad(39.0)$ & $658 \quad(38.8)$ & $515(38.4)$ & $291 \quad(36.1)$ & $126(38.4)$ & 0.587 \\
\hline West & $2,256 \quad(20.8)$ & $254 \quad(20.6)$ & $1,136 \quad(20.8)$ & $355 \quad(21.0)$ & $278 \quad(20.7)$ & $171 \quad(21.2)$ & $62 \quad(19.0)$ & 0.979 \\
\hline Unknown & $23 \quad(0.2)$ & $0 \quad(0.0)$ & $12 \quad(0.2)$ & $1 \quad(0.1)$ & $4 \quad(0.3)$ & $6 \quad(0.7)$ & $0 \quad(0.0)$ & 0.009 \\
\hline Urban residence, n (\%) & $9,312 \quad(85.7)$ & $1,039 \quad(84.1)$ & $4,690 \quad(85.9)$ & $1,451 \quad(85.6)$ & $1,162 \quad(86.7)$ & $695 \quad(86.4)$ & $274 \quad(83.4)$ & 0.350 \\
\hline
\end{tabular}

\section{APPENDIX B Baseline Clinical Characteristics (Weighted)}

\begin{tabular}{|c|c|c|c|c|c|c|c|c|}
\hline & $\begin{array}{c}\text { All Patients } \\
\mathrm{N}=10,863\end{array}$ & $\begin{array}{c}\text { Denosumab } \\
\mathrm{n}=1,235\end{array}$ & $\begin{array}{c}\text { Alendronate } \\
\mathrm{n}=5,458\end{array}$ & $\begin{array}{c}\text { Ibandronate } \\
\mathrm{n}=1,696\end{array}$ & $\begin{array}{c}\text { Risedronate } \\
\mathrm{n}=1,341\end{array}$ & $\begin{array}{c}\text { Raloxifene } \\
\mathrm{n}=805\end{array}$ & $\begin{array}{c}\text { Teriparatide } \\
\mathbf{n}=328\end{array}$ & $P$ Value $^{\mathrm{a}}$ \\
\hline CCI, mean (SD) & $0.8 \quad(1.2)$ & $0.8 \quad(1.3)$ & $0.8 \quad(1.2)$ & $0.8 \quad(1.2)$ & $0.8 \quad(1.2)$ & $0.8 \quad(1.3)$ & $0.8 \quad(1.2)$ & 0.4451 \\
\hline $\begin{array}{l}\text { Number of ICD-9-CM diagnoses, } \\
\text { mean (SD) }\end{array}$ & $13.4 \quad(8.5)$ & $13.2 \quad(8.4)$ & $13.5 \quad(8.6)$ & $13.3 \quad(8.3)$ & $13.4 \quad(8.2)$ & $13.3 \quad(7.9)$ & $(9.4)$ & 0.9185 \\
\hline Number of unique NDCs, ${ }^{\mathrm{c}}$ mean (SD) & $16.4(12.8)$ & $16.7(13.2)$ & $16.4(12.7)$ & $16.1(12.7)$ & $16.3(12.9)$ & $16.8(13.0)$ & $16.2(13.8)$ & 0.8078 \\
\hline Diagnosis of osteoporosis, n (\%) & $3,947 \quad(36.3)$ & $441 \quad(35.7)$ & $1,992(36.5)$ & $605 \quad(35.7)$ & $488(36.4)$ & $297(36.9)$ & $124(37.8)$ & 0.9637 \\
\hline Diagnosis of osteopenia, n (\%) & 1,264 (11.6) & $162(13.1)$ & $629(11.5)$ & $198(11.7)$ & $155(11.6)$ & $89(11.1)$ & $31 \quad(9.5)$ & 0.4873 \\
\hline Osteoporosis therapy, n (\%) & $3,263(30.0)$ & $376(30.4)$ & $1,640(30.0)$ & $497(29.3)$ & $397(29.6)$ & $254(31.6)$ & $99(30.3)$ & 0.9072 \\
\hline Osteoporosis-related fractures, n (\%) & $1,512 \quad(13.9)$ & $166(13.5)$ & $772(14.2)$ & $233(13.7)$ & $175(13.1)$ & $122(15.1)$ & $44(13.4)$ & 0.7971 \\
\hline Renal insufficiency, n (\%) & $446 \quad(4.1)$ & $(4.1)$ & $215 \quad(3.9)$ & $70 \quad(4.1)$ & $59 \quad(4.4)$ & $(4.8)$ & $12 \quad(3.6)$ & 0.8681 \\
\hline GI disorders, $\mathrm{n}(\%)$ & $4,178 \quad(38.5)$ & $478(38.7)$ & $2,100(38.5)$ & $633(37.3)$ & $526 \quad(39.3)$ & $321 \quad(39.9)$ & $120(36.7)$ & 0.7861 \\
\hline
\end{tabular}

ap values calculated using $\chi 2$ tests for categorical variables and analysis of variance for continuous variables across therapies.

${ }^{b}$ Number of unique ICD-9-CM diagnosis codes at the 3-digit level on medical claims.

'Number of unique NDC numbers at the generic level from outpatient pharmacy claims.

$C C I=$ Charlson Comorbidity Index; GI = gastrointestinal; ICD-9-CM= International Classification of Diseases, Ninth Revision, Clinical Modification; NDC= National Drug Code; $S D=$ standard deviation. 